\title{
Sustainable development through morphogenetic analysis: The case of Slovenia ${ }^{1}$
}

\author{
TEA GOLOB AND MATEJ MAKAROVIČ
}

\section{S sciendo}

Politics in Central Europe (ISSN: 1801-3422)

Vol. 17, No. 1

DOI: 10.2478/pce-2021-0004

\begin{abstract}
This article addresses Slovenia as a case of a post-communist country in terms of its sustainable development. It deploys an in-depth historical analysis and extensive empirical data while exploring Slovenian society through the analytical lens of morphostatic/morphogenetic approach (Archer 2017). The focus is on (1) the country's structural and cultural settings in each selected period in order to explore whether there has been a mutual reinforcement of the levels of both, contributing to the sustainable development; (2) ways in which agents respond to such changes reinforcing or changing the structural settings. The selection of quantitative structural indicators of sustainable development is based on the indicators of sustainable development that have a direct reference to the Sustainable Development Agenda of the United Nations 2030 and also adopted by the current Strategy of Development of Slovenia. The selection of survey data was based on their connection with the same sustainability issues and their availability for a longer period, particularly close to the time points of the cycles observed. The findings show that in terms of contributing to sustainable development, the presence of morphogenesis in the selected cycles turns out to be rather limited, and there is a severe lack of political reflexivity (cf. Al-Amoudi 2017) among actors.
\end{abstract}

Key words: Slovenia, morphogenetic cycles, sustainable development, economy, governance

1 This research was funded by Javna agencija za raziskovalno dejavnost Republike Slovenije (Slovenian Research Agency), grant number J5-1788. 


\section{Introduction}

In the article, we examine Slovenia as a case of a post-communist country that has undergone many social changes leading to specific developmental outcomes (Golob - Makarovič 2017). Through deploying an in-depth historical analysis and extensive empirical data, we explore Slovenian society through the lens of sustainable development indicators. We are inquiring whether Slovenia can be considered a country that has been effectively adapting sustainability goals (as proposed by the UN and also incorporated into national developmental strategies; Šooš et al. 2017) into national structural and cultural settings.

Addressing the issues of sustainable development seems to be more important than ever. The recent outbreak of the coronavirus has enormously underscored some severe weaknesses of the global social system, revealing contested and incongruent processes of modernisation. While human society has become increasingly connected in terms of consumption and cultural tastes, social integration is being loosened (Donati 2017). On the one hand, global economic flows are bound to the ideology praising continuous growth and atomised consumers, which has devastating impacts on the natural environment and social interactions. On the other, we still face the dominance of national authorities preserving their interests despite challenges whose consequences reach far beyond national borders.

The current threat of the pandemic for future economic performances and political legitimacy can only be seen as the tip of an iceberg of unsustainable politics and practices exercised on the global level and within national societies. For many decades already, human society has been facing severe social and ecological pressures. Social exclusion, inequality, and the marginalisation of particular social groups, on the one hand, and pollution, global warming, deforestation, loss of biodiversity on the other, have substantially degraded natural environment and social cohesion. Economic and political outcomes of the unprecedented situation caused by the current pandemic are likely to further deepen the cracks in the social systems caused by the unstable global geopolitical situation and destructive capitalist production. One can hardly dispute that there is a need for different social actions and reinforced solidarity among people and nations (Archer - Donati 2015; Donati 2017), which correspond to the sustainable performance on a macro level.

According to the Sustainable Development Agenda of the United Nations 2030, there is a strong need to align economic, political and technological processes with sustainable development goals. Unprecedented and rapid changes in the natural environment and technological advances require rapid and efficient adaptation to more sustainable practices. All societal levels have to be transformed and adjust quickly to be able to overcome risks and uncertainties and to assure a better quality of living for all. 
In the present article, we question in what directions Slovenia has been heading in those terms. While exploring the country in a historical perspective, we draw on Archer's (1995) morphostatic/morphogenetic (M/M) framework of society. The main advantage of this approach one can find in analytical dualism advocating the emergence of structure, culture and agency, which cannot be reduced to one another. The interaction between all levels presupposes temporal sequences, in terms that social structures and culture always predate social action. Agents respond to given context by elaborating it and enabling structural change to occur. Social context, in which actors find themselves, is thus the outcome of their past social interactions (1995). The M/M approach can also be seen as the methodological innovation (Archer - Morgan 2020) enabling agents explore different ways of morphogenetic processes between structure and culture and corresponding elaboration from actors. On the other hand, instead of the morphogenesis, the process may also be morphostatic - resulting in the maintenance of the existing structural and cultural features. In that regard, we are interested in whether structural and cultural levels have been mutually reinforcing each other in maintaining a certain status quo and preserving unsustainable practices or are bound into synergy causing transformation, thus contributing to the sustainable performance of the country.

Nowadays, we can speak about morphogenesis or morphogenetic society as an emergent global form; however, there are different morphogenetic societies existing (Al-Amoudi 2017). Via a careful examination of the historical, political and economic processes in the specific case of Slovenia, we attempt to understand the adaptation of this society to various global social changes and the contribution to these dynamics through bottom-up active participation. By that, we aim to provide some insights into broader social transformations and outcomes caused by the interplay between both structural settings and agents who are nevertheless initiators of social changes (Archer 2017; Al-Amoudi 2017). Due to globalisation and the digitalisation of social processes and interactions, exploring certain national societies entails the simultaneous consideration of its attachment (or detachment) to the wider geopolitical environments. In that regard, the analysis of Slovenia could reveal important features of both emergent levels, thus providing insights not just into the past, but also into possible future (un)sustainable practices, which are always based on pre-existing structural-cultural settings. With our analysis, we attempt to represent the historical patterns of structure and culture relations underlying the transformation of Slovenian society, and on that basis also to sketch some possible future paths to which Slovenia is heading.

\section{Sustainable development and social morphogenesis}

Sustainable development is a complex and multidimensional concept. Despite various conceptualisations, its meaning remains blurred and torn between 
scholarly definitions and political agenda. The broad explanation of its meaning has been provided by the Brundtland Commission, formerly known as the World Commission on Environment and Development, saying that 'Sustainable development is development that meets the needs of the present without compromising the ability of future generations to meet their own needs' (1987). In the article, we ensue from SOGESID's (2014) definition emphasising that sustainable development is the intertwining of environmental, economic and social sustainability. Those dimensions are also mutually interdependent. For instance, eliminating poverty among vulnerable groups calls for providing social justice and also for protecting the natural environment enabling food to grow (ISO 26000). Two additional dimensions have also been recognised, democracy and the value system of the society, which seem significant when considering sustainable development referring to the compliance of needs of present generations without hindering the possibilities of the generations yet to come (Plut 2010; Berardi 2013). What is most significant for sustainable development is its temporal, spatial and social dependence (Berardi 2013).

We are, however, aware that such definitions of sustainable development remain open to different interpretations mixing 'sufficientarian and egalitarian objectives" (cf. Boulanger 2013: 316). The present research might at first sight be seen as linked to the intragenerational dimension of sustainable development, thus promoting 'justice within the same generation' (Law 2019). However, while this study explores sustainable development through different time periods, one can see it is tightened to an intergenerational dimension as well. It has also been argued (Spijkers 2018) that Sustainable Development Goals (SDGs), which underline our conceptualisation of sustainable development, are giving reference to the 'future generations' in their orientation. What we find the most significant for sustainable development in our research is its temporal, spatial and social dependence (Berardi 2013).

To explore the interaction of social and cultural settings through time as the outcomes of morphogenetic processes leading to sustainable development, we deploy the analytical tool of the M/M approach. It has been argued (Knio 2018) that this approach is one of the most eminent accounts on exploring structure and agency interactions in social sciences, although there are not many empirical studies drawing on the $\mathrm{M} / \mathrm{M}$ approach. It has been efficiently applied in post-communist transformations studies for the case of Estonia by Lauristin - Vihalemm (2020). By using it, they analysed the social change as a multidimensional morphogenetic/morphostatic process occurring in real time, by scrutinising the interactions between structure, culture and agency by creating new developments and transformative cycles. The approach served as a methodological toolkit for considering the emerging cultural and social differences as outcomes of morphogenetic processes. Our perspective here is focused on specifically identifying these elements of morphogenesis that con- 
tribute to sustainable development. A few existing studies so far have already indicated that the $\mathrm{M} / \mathrm{M}$ approach enables a diachronic exploration of the interaction between the social context and agents. In that regard, one may refer to the analysis of the historical emergence of sustainability initiatives at Rhodes University (Togo 2009). There is also a study (Pretorius 2020) on social development referring to communities in the Nelson Mandela Bay Municipality and elsewhere in the Eastern Cape of South Africa.

There is always a precondition imposed by the structural setting which influences social action (Archer 2003; 2012). To understand the current situation (or predict a future one), the analysis of structural-cultural interactions and their interactions with agents in different periods is a key. The $M / M$ approach implies that there is always a particular structural/cultural condition (existing at the moment of time called T1) that proceeds the social action that transforms it. Structural and cultural settings are seen as emergent properties enabling situational logics in which interactions take place. This approach allows us to explore how those settings condition actors' responses. In that light, structure and individuals are different emergent levels with their own ontological reality, each possessing causal powers (Archer 2003). Both levels mutually reinforce and change themselves through their interactions (taking place in the time period of T2-T3), while the approach allows us to move towards the contextualisation of these interactions. However, change occurs only through the elaboration (T4) of social context by social actors or agents who consider their intentions and future concerns through reflexive internal conversation (Archer 2003; 2007). Elaborated social context thus becomes a new T1. The repetitiveness of such dynamic elaboration between societal levels creates a morphogenetic cycle. However, if the elaboration fails and the old culture and structure are maintained, the cycle is morphostatic.

Due to the compression of time and space (Harvey 1989), accelerated digitalisation and mass communication, people have become increasingly embedded in novel social configurations and not-yet-tested solutions for effective action (Archer 2012; Al-Amoudi 2017). Accordingly, they are encouraged or even forced to become more reflexive in order to adapt successfully to rapid changes. It has been argued that the variety in ideas, techniques, skills, products and lifestyles (Archer 2017:3) are contributing to the morphogenetic society, in which reflexivity is an imperative (2012).

Slovenia should be seen in the context of the wider (global) morphogenetic process, and it is thus not excluded from such transformations. However, there are also specifics in how the national society responds to such imperatives in terms of sustainable performances. Not everyone is capable of elaborating the social context, which is preconditioned with the structural and institutional aspects, such as 'human subjects require institutional help' to realise their concerns' (Maccarini 2017). For instance, it has already been shown in the 
case of Slovenia that structure has a significant impact on the intensity and substance of reflexive outcomes (Golob - Makarovič 2019). In general, one can find substantial doubts that morphogenetic processes empower people. It has been argued that reflexive powers, enabling interpretation and acting upon the social configurations are not equally distributed (Al-Amoudi, 2017: 73).

In that regard, Archer (2007) has shown that there are four different modes of reflexivity that one practices: (a) communicative reflexivity, which needs to be confirmed and completed by others before it leads to action; (b) autonomous reflexivity, which stems from an unstable initial context; (c) meta-reflexivity, which critically evaluates previous inner dialogues, and is critical about effective action; (d) fractured reflexivity, which cannot lead to purposeful courses of action and only intensifies personal distress and disorientation. Reflexivity occurs within the inner dialogue of individuals. As Archer says, it is 'the regular exercise of the mental ability, shared by all normal people, to consider themselves in relation to their (social) contexts and vice versa' (Archer 2007: 4). While reflexivity is always a personal emergent power, the kind of social contexts in which one is deliberating his/her concerns and actions is important. As this article focuses on the elaboration of sustainable development goals referring to the individual and macro-societal adaptation to sustainable performance, the distinction between Al-Amoudi's (2017) social and political reflexivity seems to be crucial. Social reflexivity primarily addresses the question 'How should I make my way through life?', which is explored in detail in Archer's works. Political reflexivity, in contrast, refers to the question, 'How can we steer society together?' This perspective resonates closely with Donati's relational reflexivity, emphasising the importance of recognising common concerns and acting together in a certain way. Both kinds of reflexivity should be present within society to expect significant morphogenetic transformations, as they 'result from people performing the practices and respecting the rights and duties associated with their roles' (Al-Amoudi 2017: 68).

In that regard, when analysing different periods that distinctly characterised Slovenian society, we do not presuppose that each period has been morphogenetic in terms of sustainable development. The latter implies that mechanisms generating changes are prevailing over those that maintain social stability. As Al-Amoudi (2017) emphasises, in that term, transformational mechanisms are not exogenous but endogenous, which means that changes result from people performing the practices (Al-Amoudi 2017). While transformations can be induced from the external factors, which is quite obvious in the case of Slovenia, where the processes, such as marketisation and Europeanisation, reflected transformations in a broader context. However, what comes next is crucial, referring to the ways in which actors and agents respond to such changes, reinforcing or changing structural settings. There is an interaction between structure-culture-agency (SAC) that matters. 
In this article, we explore the macro-level of Slovenia by referring to a variety of existing research, typically dealing with post-communist transformation, development and sustainability. While official statistics can provide some quantitative insights into the social structure, general attitudes of the population as measured by social surveys provide some quantitative proxy indicators of selected aspects of culture. The quantitative structural indicators of sustainable development that we refer to are selected in direct reference to the Sustainable Development Agenda of the United Nations 2030, which were also adopted explicitly by the current Strategy of Development of Slovenia 2030 (Šooš et al. 2017).

The selection of survey data is also based on their connection with the same sustainability issues and their availability for the longer period, particularly close to the time points that we observed, specifically the beginnings and ends of the cycles. These data should not be seen as 'objective' proof of our claims but as an additional reference that supports our analysis, which is otherwise more of an interpretative and qualitative nature.

We deliberately begin our analysis in 1992, right after Slovenia was recognised as an independent country and after multi-party representative democracy had been consolidated by the first democratic constitution. The period between the first signs of the crumbling of the Yugoslav communist regime and the consolidation of Slovenian statehood was so strongly focused on the basis of democratisation and nation-building that, other than the obvious general concerns about providing a good life in a new social order, no major focus could be given to either of the developmental issues. The year 1992 represents a turning point and a clear beginning of a new cycle from that perspective: with the representative democracy and statehood practically granted, the developmental issues could become the central focus.

The year 2008 can be seen as another major turning point. It represented the peak in terms of Slovenian economic development in relative terms. It symbolically concluded its 'Europeanisation' by holding the EU Presidency that year, thus reaching all of its goals in these terms. In contrast, that year marked the beginning of the global economic crisis that seriously affected Slovenia, not only in economic but even more so in terms of governance and institutional trust.

This brings us to the next major turning point of 2013. If 2008 could be seen as 'a peak' in certain ways, 2013 could be seen as the lowest point, characterised by austerity measures, political crisis, massive distrust towards the elites and the institutions, also manifested through street protests, even some minor elements of violence. However, it was also the beginning of the recovery and even the search for new paradigms. It is too early to speculate about the next turning point and the end of the current cycle, though it is very likely that it will be at least to some extent related to coronavirus-related changes. 
In principle, we can thus distinguish between three distinctive cycles within our period or research that can be analysed through morphostatic/morphogenetic lenses:

- the Marketisation or Europeanisation Cycle (1992-2008) characterised by the consolidation of the market economy, following the references from the developed European countries and integrating into the European Union;

- the Crisis Cycle (2008-2013), characterised by economic decline, rising distrust towards the elites, towards political and legal institutions, and the crises of governance; and

- the Search for New Alternatives Cycle (from 2013), characterised by the post-crisis recovery but the lack of clear references or a broadly accepted developmental models to follow.

These cycles are not defined based on any particular quantitative indicators, but on the visible historical turning points. Thus, it is up to the further analysis in this article to test whether and how these distinctive cycles also correspond to the trends and shifts in terms of the aspects of sustainable development. We will also briefly indicate the links between developmental failures and governance crises.

It should also be noted that the national cycles we distinguish significantly, but not fully, correspond to some global cycles and turning points. While the 2008 crisis was global, the timing of the turning points in 1992 and 2013 were more nationally specific, but still resonating, ether more or less directly, some of the transnational phenomena inspired by the events such as the fall of the Berlin Wall in 1989 or the Occupy movement in 2011. Although the distinction between inside and outside may be quite blurred in the era of globalisation (Robertson 2014; Adam 2020), we should still distinguish at least for analytical purposes between the exogenous and the endogenous structural and cultural conditions affecting each of the cycles.

If we observe all of the dimensions of sustainability understood in holistic terms such as combining the economic, the social and the natural-environmental perspectives, we can observe both the elements of morphogenesis and the elements of morphostasis over the previous three decades. Furthermore, these three dimensions of sustainable development cannot be studied without considering the major aspects of governance, which involves both the participatory and deliberative consensus-seeking mechanisms and the capacities for the efficient implementation of the adopted decisions, which would be close to Amitai Etzioni's ideal of the active society (Etzioni 1968).

While some aspects of sustainable development in Slovenia were quite vibrant in the given periods, others were stagnant or simply neglected. We assume that the generative mechanisms that produced either morphogenetic or morphostatic outcomes in terms of sustainable development can be best understood in the broader context of the more general cycles of the Slovenian society as specified above. 


\section{Marketisation and Europeanisation Cycle}

The initial structural conditions at the beginning of this cycle (time point $\mathrm{T} 1 \mathrm{in}$ Archer's morphogenetic/morphostatic analytical tool) was the industry inherited from the communist system and mostly unfit for global market competition. Nevertheless, Slovenia had some initial benefits at that time when compared to other communist countries. Enterprises were comparatively more autonomous due to 'self-management socialism', and some parts of the industry were already oriented towards the Western and other global markets (Adam et al. 2005; Crowley - Stanojević 2011: 275; Susan L. Woodward 1995). With comparatively low levels of social exclusion and high levels of ethnic homogeneity, especially when compared to the other ex-Yugoslav republics (Mrak et al. 2004), society was rather cohesive. Most of the business was formally 'socially' owned, which in practice meant state-owned but with high autonomy of the managerial structures, mostly holding their posts from communist times (Adam - Tomšič 2000: 144).

Despite the crises caused by the problems of the old uncompetitive companies and the first suspicious privatisation manoeuvres, the society remained comparatively egalitarian. This structural equality went hand-in-hand with the traditional cultural features of Slovenian society strongly supporting egalitarianism, described by Josip Županov as the 'egalitarian syndrome' (cf. Štulhofer Burić 2015). In terms of general cultural conditions, there was comparatively broad and homogeneous support for the common national project, which could be described as 'joining Europe', which involved not only the ambition to join the European Union in institutional terms but also to adopt European qualities and European ways of life (Velikonja 1996; Golob 2013), which were seen as consistent with what the proper Slovenian way should be.

These initial cultural settings were rather consistent with the external cultural and structural conditions within the European Union at the time, which favoured eastern enlargement, and accepting guidance from Brussels was seen as acceptable from the Slovenian cultural and structural perspectives.

Like most other transitional societies, Slovenia underwent substantial structural transformations, while as Domazet, Marinović, and Jerolimov (2014: 20) argue, the shift towards sustainability should be seen as a process of adaptation, learning and action demanded upon by scholars to consider the dynamic relations between economy, society and the natural environment.

From the perspective of sustainable development, the initial conditions provided a strong generative mechanism towards increasing economic development (due to the broad acceptance of the marketisation/Europeanisation goals), not damaging the social cohesion (egalitarianism) but ignoring the natural environmental aspects (having no particular cultural or structural support). A strong cultural emphasis was placed on hard work and the reduction of lagging in terms of cognitive mobilisation (Adam et al. 2005), productivity and material standards. 
The key political and other agents broadly shared these views. Significant political polarisation between the centre-left and the centre-right political actors was mostly defined in cultural terms, like an ideological-historical Kulturkampf (Adam et al., 2009; cf. Balázs et al. 2018: 278-279), but seldom regarding the key developmental orientations. This was manifested through strong continuity of these policies, which were run for most of the period by the centre-left governments, but never really changed in this regard when the government was taken by the centre-right first briefly in 2000 and then again from 2004 to 2008 (Adam et al. 2009). Despite the overall stress on economic growth, the balance between the key agents never allowed any significant move towards more radical market reforms and neoliberal economic policies. In this regard, the major role was played by the strong veto power of the trade unions within the established structure (and culture) of neo-corporatist arrangements, combined with the constitutional arrangement allowing to call a referendum against any undesired legal measures (Crowley - Stanojević 2011; Meszmann 2007). More radically neoliberal discourses promoted by the 'Young Economists' were only a brief variation in the dominant discourses during the first years of the centre-right government; however, they never prevailed as an actual policy despite getting some resonance in the Strategy of the Republic of Slovenia from 2005 (cf. Šušteršič - Rojec - Korenika 2005). The obvious emphasis of the key agents was thus on encouraging economic development while maintaining social sustainability, with the latter seen mostly as maintaining status quo through the highly regulated labour market, at least when compared to most of the other post-communist countries in Europe (Crowley - Stanojević 2011).

The focus on market reforms favouring economic growth was also expressed in the first major general strategic developmental document The Strategy of Development of Slovenia based on the Lisbon Strategy (Šušteršič - Rojec Korenika 2005). Its strong emphasis on the economic aspects of development is more than indicative. While this was complemented with social (welfare) concerns, only the last of the five priorities explicitly mentioned sustainability but focused more on generational and regional disparities than on the natural environment. However, as indicated later (Republic of Slovenia, Ministry of Economy 2013), not even the existing environmental goals were met.

The lack of environmental concerns in this cycle was not only a result of structural and cultural conditions but also of the lack of agency. While the Greens of Slovenia were initially represented in the parliament and even a constituent part of the first democratic Slovenian government, their focus on closing-down the only Slovenian nuclear powerplant (which would have no sustainable alternatives) and the lack of other significant ecological topics they could enforce as a broader agenda led to their eventual political failure early in the 1990s. The environmental agenda thus became even more marginalised and limited to some relatively fringe elements of civil society. 
However, as far at the economic and social dimensions of development were concerned, the cycle drew from the high levels of political reflexivity established in the late 1980s and elaborated through further reflexive considerations. They resulted from relatively participatory movements and subsequent consensus-building capacities regarding nation-state building, its democratisation and its political and economic integration in the European framework. The cultural and structural references were to a great extent exogeneous ('joining Europe'), but highly domesticated for the purposes of a morphogenetic structural transformation.

The agency that took place within this period (from T2 to T3 in terms of Archer's framework) thus clearly led to morphogenetic results at the final point of the cycle in terms of structural elaboration (T4), transforming Slovenian society into an integrated part of the EU system of the economy and governance quite competitive globally in the economic terms. Slovenians ended the cycle being significantly more educated and economically productive, both in comparison to the beginning of the cycle and to the European average. This can also be well observed in terms of GDP per capita growth from 1992 to 2008 in absolute and in relative terms when compared to the mean of the EU countries as indicated in Figure 1.

\section{Figure 1: Selected structural aspects of development}

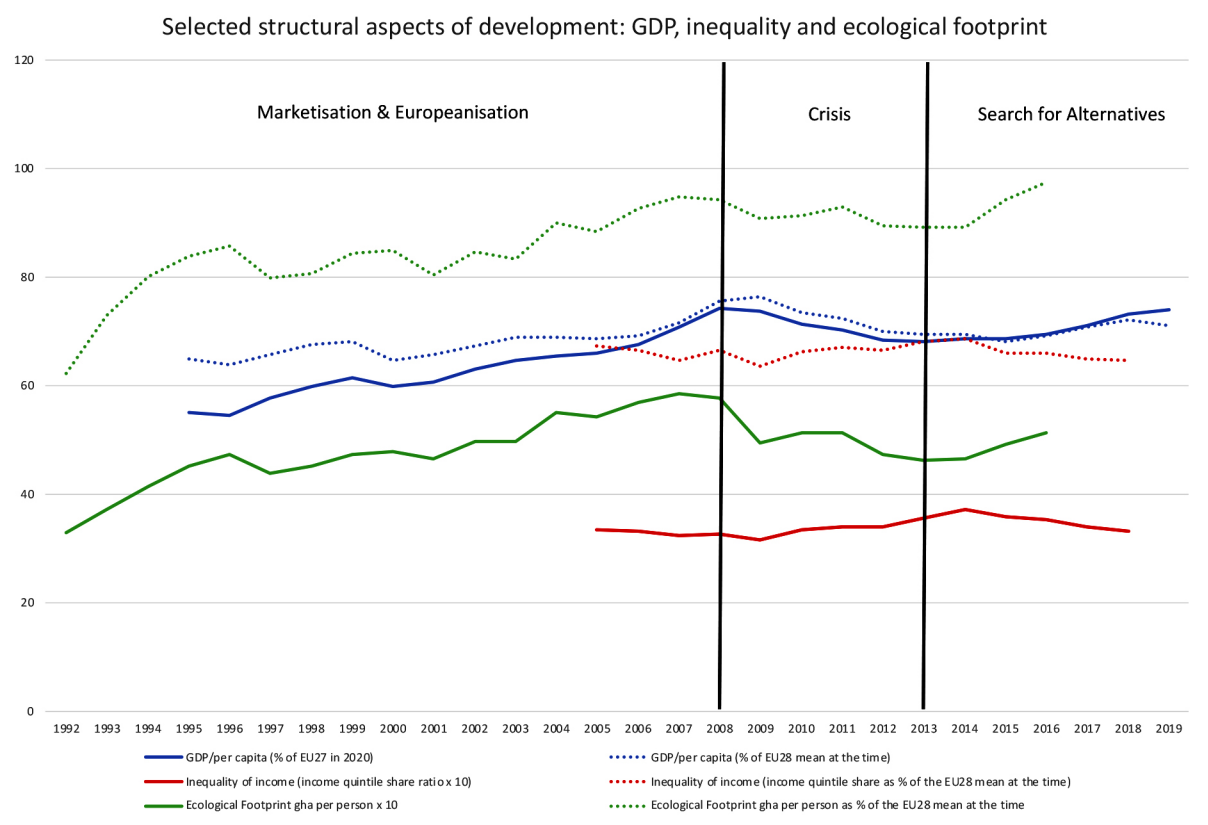

Sources: Eurostat (2019); Global Footprint Network (2019); own calculations. 
However, while these shifts demonstrate the morphogenetic change during this cycle in terms of economic development and European integration of Slovenia, one cannot see it as a morphogenetic change providing a clear step towards an overall sustainability in terms of all of its three dimensions.

While the general (cultural) attitudes of the population supported economic change at the beginning of the cycle and expressed relatively positive views about the results at the end of it, the worries about social equality have persisted (obviously related to the concerns about the negative social consequences of the market economy). Both are indicated by the survey results on the attitudes towards the economic system and on inequality in Figure $2 .{ }^{2}$ However, the levels of social exclusion have remained low, and quite impressive levels of income equality persisted (see the data on inequality in Figure 1). In terms of preserving the social status quo, the first cycle can be seen as morphostatic.

As indicated above, in terms of culture, structure and agency, environmental concerns were not a major concern in this cycle, neither in Slovenia nor in its broader European structural and cultural context. Moreover, while the feelings of (individual) responsibility for the environment have decreased during the cycle (see data about individual responsibility in Figure 2), the ecological footprint has increased consistently with the GDP growth (see Figure 1).

This is quite in line with the existing research. It has been argued (Pravdić 1997: 209) that transitional societies have struggled to accept the market economy as an open system embedded into a finite and closed global or regional ecosystems. Those countries, including Slovenia, were struggling to establish a new and different value system entailing also the proper concern for the management of natural resources. Even more challenging was devoting financial, technical means to implement such principles, to a large extent due to the lack of political will (Pravdić 1997: 201). Domzet - Marinović Jerolimov (2014: 35) have also observed that the post-communist central and east European regions are facing some specific and inherent obstacles towards the sustainability. The latter is hindered mainly by the specific structural flaws linked to the historical

2 In order to make the variety of survey data comparable, they are presented in terms of standard deviations from the means of the European countries included in a given survey. The means have been calculated from the Likert scales obtained through the surveys, namely:

- Satisfaction with the economy: 'Economic system needs fundamental changes' (reversed scale, EVS 1990-1992) and 'How satisfied with present state of economy in [country]' (ESS Round 42008; ESS Round 72014; ESS Round 92018)

- Support for greater equality: 'incomes should be made more equal' vs. 'there should be greater incentives for individual effort' (EVS 1990-1992), 'Government should reduce differences in income levels' (ESS Round 42008; ESS Round 72014; ESS Round 92018)

- Individual responsibility for environment: 'I would give part of my income if I were certain that the money would be used to prevent environmental pollution' (EVS 1990-1992), 'As an individual, you can play a role in protecting the environment in [our country]' (Eurobarometer 2008; 2014; 2017)

- Trust in the national parliament: 'how much confidence you have in parliament' (EVS 1990-1992), 'how much you personally trust...[country's] parliament' (ESS Round 42008; ESS Round 72014; ESS Round 92018). 
socialist industrialisation in the past and to the more recent changes in the civil participation limited to economic activity.

\section{Figure 2: Selected cultural aspects of development}

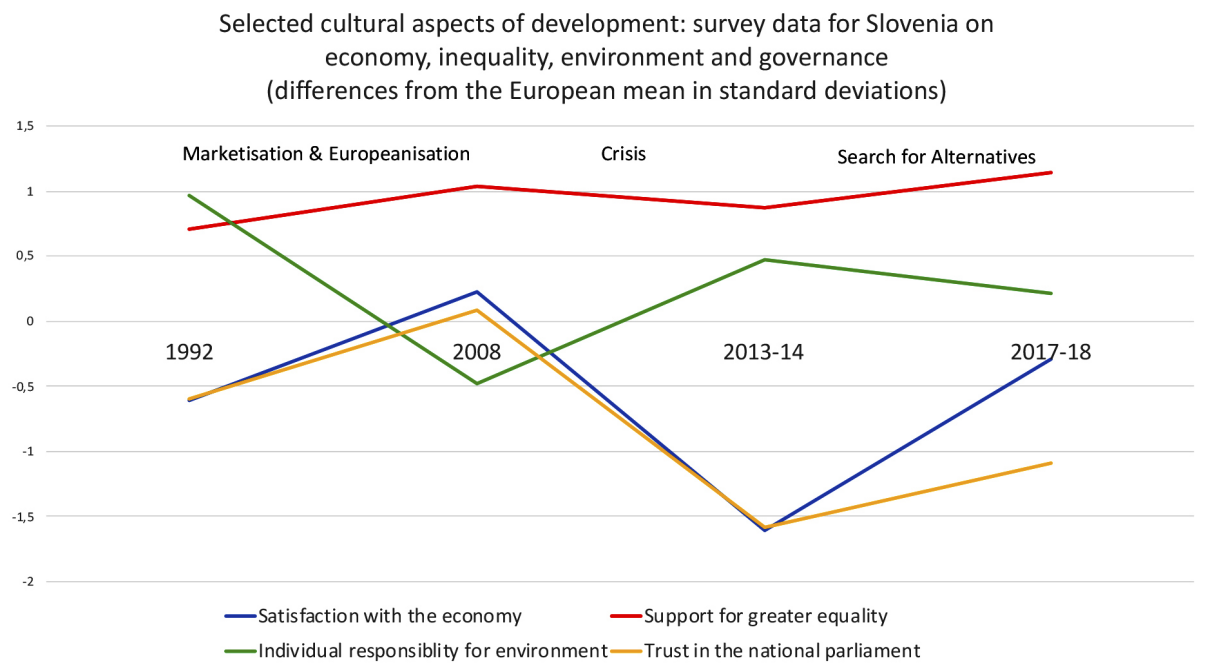

Sources: European Values Study (1992); Special Eurobarometer reports (2008; 2014; 2019); ESS Round 4 (2008); ESS Round 7 (2014); ESS Round 9 (2018); own calculations.

\section{The Crisis Cycle}

While the integration of Slovenia into the European and Euro-Atlantic framework was a clear outcome of the match of the structural and cultural causal mechanisms and the deliberate agency, implementing the global and national ideas of a proper post-communist transition, the Crisis Cycle that followed was quite different. In Archer's morphogenetic/morphostatic analytical approach, the ending Point 4 of the previous cycle becomes the starting Point 1 of the new cycle. The Slovenian situation was quite consistent with that, as the key outcomes of the Marketisation/Europeanisation cycle became the major generative mechanisms of the new Crisis Cycle.

At least to some extent, it can be argued that Slovenian society paradoxically became a victim of its previous success (Spruk 2012; Tomšič - Vehovar 2012). Firstly, its successful integration into European and global markets made it even more susceptible to the global economic crisis in 2008 and the subsequent years. Secondly, the initial goals of nation-building, democratisation, functioning economy and European integration as a unifying narrative 
transcending political, social and economic divisions were achieved and could thus provide no clear common guidance for the further (political) agency. Finally, despite the significant improvement of material welfare, there was also a kind of disillusionment with the Western ideals of prosperity and democracy, again contributing to the weakening of the previously unifying narrative. If the first element of this causal mechanism of the crisis can be seen as structural, the other two can be seen as cultural.

In the complex arrangements combining representative democracy with neo-corporatist social dialogue (Guardiancich 2011; Crowley - Stanojević 2011), the variety and political, economic and social actors attempted to maintain a balance between (delayed) austerity measures, maintaining social cohesion and economic recovery. The developmental goals of the Strategy of Development of Slovenia 2005-2013 have started to be seen as unachievable (Republic of Slovenia, Ministry of Economy 2013).

The Slovenian manifestations of the financial and economic crises caused an even more critical legitimacy crisis of political actors, which also became a legitimacy crisis of the institutions, such as the government, parliament and political parties in general and the judicial system (see the drastic decline regarding trust in the parliament from 2008 to 2013 in Figure 2). The public perception of both the political and the judicial actors, strongly encouraged by not only mass media and civil society actors but also by political actors themselves, increasingly became marked by inefficiency and/or corruption. Record low trust in the political and judicial institutions was one of the most obvious outcomes of the Crisis Cycle.

The institutional and political crisis culminated in the 'popular uprisings' against the 'corrupt elites' in 2013. While the narratives of the 'uprisings' sometimes even challenged the logic of representative democracy itself and vilified the elites, in general they were more specifically targeted against one of the mayors and the centre-right government at the time. Consequently, after the return of the centre-left actors to power, the protest movement quickly disappeared, and the political system seemed mostly re-consolidated.

The exhaustion of the classical nation building-democratisation-Europeanisation narratives during the Crisis, however, would require a higher level of political reflexivity. The crisis did not produce any major reflexive re-considerations, neither among the elite actors, within civil society, nor among the agency provided by the 'ordinary' people participating in the protests. What seemed to be 'critical' and protest-orientated seemed to be based more on a combination of the traditional culture of anti-elitist egalitarianism, pre-existing ideological polarisation, communist nostalgia and (but only to a limited extent) some resonance referring to the transnational phenomena such as the Occupy movement. As far as the 'anti-systemic' protests were reflexive, they were mostly led by communicative reflexivity (following what the others would confirm through 
the conventional and on-line social media) and fractured reflexivity (feelings of disillusionment but with no clear search for alternatives).

Consequently, the disillusionment with marketisation and the problems with the economic crisis significantly affected governance legitimacy and even capacities but provided no viable alternative narratives. It was indicative that the new Strategy of Development of Slovenia 2014-2020 was only drafted, and that the centre-left government taking power in 2013 after the 'popular uprisings' mostly merely continued with the implementation of the austerity measures adopted previously by the centre-right government.

Far from surprising, regarding the developmental outcomes of this cycle, the economic crisis eroded the economic indicators, while the political-institutional crisis had devastating effects on institutional trust (see Table 2); thus, the governance capacities to intentionally steer any kind of sustainable development clearly decreased with this cycle. Despite some increase of inequality during the crisis, a comparatively high level of social cohesion based on egalitarianism and relatively high social inclusion was maintained.

The environmental issues were occasionally brought forward by particular NGOs and some local initiatives, but they never became one of the central narratives leading the key actors. The general feeling of civic responsibility for the environment increased when compared with the previous cycle, but, as this was not transferred into any consistent general policies, the structural improvement of the environmental indicators was more a result of the decrease in industrial production due to the economic crisis than of any deliberate environmentalist concerns, as became evident after the economic crisis was over (see the temporary decline/stagnation of the ecological footprint during the Crisis Cycle in Figure 1).

In terms of its outcomes, the cycle can thus be seen as morphostatic: despite the severe problems with the persisting narratives, the increase of disillusionment and protest, no viable alternatives were provided to the classical narratives from before 2008 (which is in stark contrast to the alternatives in terms of nation building-democracy-Europe provided at the end of the 1980s against the communist regime, which were quite clearly elaborated and also mostly implemented between 1989 and 2008). The failure of the governments in 2013 even to adopt a new overall strategic document was symbolic but highly indicative in this regard.

\section{The Cycle of Searching for Alternatives}

In terms of structural conditions, at the beginning of the new cycle Slovenia was still severely affected by the economic crisis, but the mass protests had dissipated, and the focus returned to the conventional institutions of representative democracy. In cultural terms, however, the confidence towards both political and judicial institutions was severely damaged and, with the declining institutional 
confidence and the lack of any clear unifying narratives, the relations between the political agents were even more polarised than in the previous cycles.

Structural conditions indicated not just an economic crisis but also the exhaustion of the classical modernising narrative from the first cycle that focused almost exclusively on economic growth while maintaining the social status quo. Structurally, the issues were further complicated when the economic crisis was followed by the 'refugee crisis'. In general, the structural pressure to reconsider the relationship between the economic, social and environmental aspects of development and to combine them with participatory and effective governance became clearer than ever before. This definitely called for higher levels of political reflexivity.

However, neither the prevailing cultural conditions nor the composition of the (strongly polarising) political, mass media and civil society agents provided proper circumstances for this. It is indicative that the prevailing discourse as represented through the media was not about debating new visions but about searching for 'new faces'. Lacking the necessary political reflexivity, politics became strongly personalised (Cabada - Tomšič 2016). In the centre-right, this has been manifested by the continuing inseparability between the party and its leader, regardless of the circumstances. In the centre-left, it was manifested by establishing parties for a single-election use centred exclusively on the leader (indicatively with the party being named after its leader). Instead of a vision that could be reflected upon, the leader was typically idealised by supposedly embodying a certain personal feature, such as 'decisiveness', 'entrepreneurial efficiency', 'uncompromising ethic' or maybe just being close to the 'ordinary people' (Tomšič - Prijon 2013).

This combination of structural challenges with the cultural features of disillusionment, disorientation and institutional distrust in principle provided fertile ground for the rise of populism (cf. Adam - Tomšič 2019) that could provide non-reflexive shortcuts by responding with simplistic answers to complex issues, with the economic crisis providing new grounds for leftist populism, the refugee crisis for the right-wing populism and the broader systemic crises for both of them. However, despite certain integrations of some right-wing xenophobic agenda into the main centre-right party and the formation of a new party of the radical left, no new major actors were present that would make use of these factors to develop an extremist right-wing or extremist left-wing agenda. Despite the structural and cultural conditions there was, fortunately, in this case, the lack of significant agency that would build more on that. Populism was thus mostly present through the personification of politics, as mentioned above, not in any significant way in the form of political extremism.

There have also been some of the more positive exogenous structural and cultural conditions affecting this cycle in Slovenia. The global economic recovery has contributed to the post-crisis recovery of the Slovenian economy, though 
Slovenia's economic GDP per capita in comparison to the rest of the EU, is still significantly below the level of 2008 (Šooš et al. 2017: 10). The global rise of environmentalist discourse provides another major cultural impetus for Slovenian society, though its actual adoption by the major actors is still very questionable.

The adoption of the Strategy of Development of Slovenia 2030 (Šooš et al. 2017) in 2017 has been an encouraging sign because it clearly emphasises the synergy between the economic, social and environmental aspects of development, combined with the focus on governance. In the context of the above-mentioned exogenous structural and cultural mechanisms, the document draws heavily from the Agenda 2030 of the United Nations and EU documents. However, it is premature to predict whether these will be the start of another morphogenetic transformation in terms of actually implementing a developmental paradigm, or it will just be seen as an attempt at externally imposed discourse, suppressed due to domestic actors' vested interests.

The recent developmental indicators for this cycle thus far, in Table 3, confirm a moderate economic structural recovery and greater economic optimism in the cultural sphere as the current (but not necessarily final) outcomes of this cycle. They are combined with significant scepticism towards digital technology in comparison to the European average, but it cannot be predicted if this will also lead to any significant politically reflexive deliberations (some have been present in the debates on the health effect of G5 technology but not as a major political issue). Egalitarianism and social cohesion have remained comparatively high in structural and cultural terms, while no major improvement can be seen regarding the structural and cultural aspects of protecting the natural environment (see Figures 1 and 2).

We cannot speak yet about any clear end of this cycle. It has thus far failed to produce any type of cultural and structural elaboration in term of morphogenesis, and it is still premature to describe it as fully morphostatic, though the status quo has clearly prevailed over change thus far. Likely, a global turning point starting a new cycle based on the coronavirus effects will also conclude the existing and start the next cycle, also in terms of sustainable development. Although the structural and cultural contours initiating the new cycle are becoming clearer, what the actual effects of this future cycle for sustainable development will be is mostly a matter of agency, especially of the globally powerful actors.

\section{Conclusion}

This study has provided insights into the transformative processes in Slovenia as a post-communist society from the perspective of sustainable development. Focusing on a post-communist country is of particular relevance in this regard as the transformative nature of these societies may provide some significant features potentially relevant for sustainable performance in general - due to 
their specific historic heritage and path-dependencies (Domazet - Marinović Jerolimov 2014). The key innovative contribution of the text is therefore in applying a morphostatic/morphogenetic approach to such a concrete empirical case, thus enabling to observe how the interaction between structure and culture contributes either to a morphogenetic social change or to the status quo maintenance. The role of the political elites and other actors in the elaboration of the given circumstances has been taken into account. Consequently, we have been able to explain which of the historical periods were actually morphogenetic in terms of sustainable development.

We can speak of various aspects of social transformations in terms of morphogenesis over the previous three decades in Slovenia. However, while social morphogenesis is needed for the shift from the existing non-sustainable practices, clearly morphogenesis often does not produce greater sustainability.

Thus, in terms of contributing to sustainable development, the presence of morphogenesis in the cycles that we have analysed turns out to be rather limited. Based on this result, we can conclude that morphogenesis undoubtedly occurred in the first cycle of Marketisation and Europeanisation, but only in terms of economic development and European integration. In this period, Slovenian society aligned itself with the EU standards of governance and developed a functioning market economy, while at the same time the social aspects of sustainability were not compromised in any significant way. The previous 'socialist-style' model was replaced by the model that produced impressive economic results, while still maintaining comparatively high levels of equality and social inclusion. The continuation of the common nation-building narrative, further elaborated in the 'Europeanisation' narrative based on broad popular support made the agency predominantly endogenous. We can thus clearly see this as a case of morphogenesis. Moreover, we can see it as morphogenetic change contributing to greater economic welfare. However, we should also mention in this regard that the social aspect was limited to the maintenance of the status quo, while the environmental one was largely neglected both in cultural and structural terms.

In the two other cycles that followed, we observe that factor of social change was more exogenous without the ability of the wider population to become engaged in the elaboration of structural settings. The impetus for change came almost exclusively from outside (for example through the crisis and post-crisis recovery in structural terms or the discourses of anti-elite protest and greater environmental awareness in cultural terms. Political and economic elites have mainly adjusted to external circumstances to maintain the status quo, mostly restoring the previous situation, which was particularly clear with the shift from the second to the (to date) final cycle, when typically only 'new faces' (clearly symbolising the superficial nature of political change) were offered instead of increased political reflexivity that could lead to any kind of paradigmatic change in terms of sustainable development. 
Nevertheless, these do not indicate that Slovenian society is not sustainable at all, as the results are often ambivalent, indicating that the future is uncertain. It depends significantly on the broader Slovenian population, whether it is (of course, while still being influenced by exogeneous factors) reflects the new paradigmatic shifts and support new visions of sustainable development, balancing the economic, social and environmental aspects, which depends strongly on the mode of reflexivity, especially the predominance of meta reflexivity (Al-Amoudi 2017). While the latter seems to be quite present at the micro-level in people's everyday concerns, as indicated by previous research (Golob - Makarovič 2019), there seems to be the problem of transforming these everyday life concerns to broader political concerns. Understanding this gap would require further research.

There are serious concerns regarding all of the aspects of sustainable development. Even the economic achievements from the Marketisation and Europeanisation Cycle cannot be taken for granted as the highest GDP per capita in Slovenia relative to the EU average was achieved in 2008 (90\%), while in subsequent years the gap between Slovenia and the EU average has only increased; Slovenia even fell from the first to the second place in economic terms among the post-communist EU members (with Czechia taking the lead) (Eurostat in Lauristin - Vihalemm 2020).

The environmental dimension is even more ambivalent. On the one hand, we can observe an increased culture of individual responsibility manifested not only in survey data (see Figure 2) but also in everyday behaviour such as very prevalent care for waste separation and, structurally, in terms of persistently high water-quality. On the other hand, severe structural barriers and strong vested interests, typically focused on coal extraction, import and use as a source of energy, are preventing any significant structural transformation in terms of decreased carbon emission. This can be exemplified by the persistent reliance on domestic and imported coal. It is also strongly related to the confusion about the alternatives, with the decision of building another nuclear power plant potentially postponed until 2027 and with having no large-scale alternatives available to coal as the major source of electric power (cf. Reuters 2020). Despite some good results in the present, the future thus remains highly uncertain.

This can also be argued for social sustainability that seems impressive when we focus on egalitarianism, low exclusion and low poverty (Government Communication Office 2019). However, the ageing of the population and the lack of more consistent immigration policies (also as a broader EU problem) may jeopardise this sustainability in the long run. In addition, the strong culture of egalitarianism may contradict the meritocratic principles (Adam 2020). This kind of 'absolute equality' may block the development of 'far-reaching equality' as a condition for a good society (Sayer 2011, in Archer 2017) based on the idea 
of joint participation in the creation of the relational goods that can only be truly enjoyed through participation (Archer 2017; Donati 2017).

This kind of broad participation, especially based on bottom-up initiatives and strengthening of the intermediate institutions (Archer - Donati 2015), would also provide the best way of morphogenetic change towards a more sustainable developmental model. Its actual potential in Slovenia, however, would need to be assessed through further research.

\section{References}

Adam, Frane - Makarovič, Matej - Rončević, Borut - Tomšič, Matevž (2005): The Challenges of Sustained Development: The Role of Socio-cultural Factors in East-Central Europe. Central European University Press.

Adam, Frane - Kristan, Primož - Tomšič, Matevž (2009): Varieties of Capitalism in Eastern Europe (With a Special Emphasis on Estonia and Slovenia). Communist and Post-Communist Studies, 42 (1): 65-81.

Adam, Frane - Tomšič, Matevž (2000): Transition Elites: Catalysts of Social Innovation or Rent Seekers (Reproduction-Circulation Thesis Reconsidered). Druzboslovne razprave, 16 (32-33): 139-160.

Adam, Frane - Tomšič, Matevž (2019): The future of populism in a comparative European and global context. Comparative sociology 18 (5/6): 687-705.

Adam, Frane (2020): Med meritokracijo in populizmom: O kakofoniji podatkov v postfaktični družbi. Inštitut za razvojne in strateške analize, Ljubljana.

Al-Amoudi, Ismael (2017): Reflexivity in a Just Morphogenic Society: A Sociological Contribution to Political Philosophy, in: Margaret Archer, ed., Morphogenesis and Human Fluorishing, 63-92, Springer International Publishing.

Archer, Margaret (1995): Realist social theory: The morphogenetic approach. Cambridge: Cambridge University Press.

Archer, Margaret (2003): Structure, Agency and the Internal Conversation, Cambridge University Press, Cambridge and New York.

Archer, Margaret (2007): Making Our Way through the World: Human Reflexivity and Social Mobility, Cambridge University Press, Cambridge and New York.

Archer, Margaret (2012): The Reflexive Imperative in Late Modernity. Cambridge University Press, Cambridge and New York.

Archer, Margaret (2017): Introduction: Has a Morphogenetic Society Arrived. in: Margaret Archer, ed., Morphogenesis and Human Fluorishing, 1-28, Springer International Publishing

Archer, Margaret, and Pierpaolo Donati (2015): The Relational Subject. Cambridge University Press, Cambridge and New York. 
Archer, Margaret - Morgan, Jamie (2020): Contributions to realist social theory: an interview with Margaret S. Archer. Journal of Critical Realism. DOI: 10.1080/14767430.2020.1732760.

Balázs Trencsenyi - Kopeček, Michal - Lisjak Gabrijelčič, Luka, Falina, Maria - Baár, Mónika (2018): A History of Modern Political Thought in East Central Europe, Volume II: Negotiating Modernity in the 'Short Twentieth Century' and Beyond, Part Il: 1968-2018, Oxford University Press, Oxford.

Berardi, Umberto (2013). Clarifying the new interpretations of the concept of sustainable building. Sustainable Cities and Society, (8), 72-78.

Boulanger, Paul Marie (2013): Sustainable development as practical intragenerational and intergenerational justice: Interpretations, requirements, and indicators. In: Merle, Jean-Christophe ed., Spheres of Global Justice, 713-733, Springer International Publishing.

Cabada, Ladislav - Tomšič, Matevž (2016): The Rise of person-based politics in the new democracies: The Czech Republic and Slovenia. Politics in Central Europe 12 (2): 29-50.

Crowley, Stephen - Stanojević, Miroslav (2011): Varieties of Capitalism, Power Resources, and Historical Legacies: Explaining the Slovenian Exception. Politics \& Society 39 (2): 268-295.

Domazet, Mladen - Marinović Jerolimov, Dinka (2014): Sustainability Perspectives from the European Semi-Periphery. Institute for Social Research in Zagreb Heinrich Böll Stiftung Hrvatska.

Donati, Pierpaolo (2017): What Does a 'Good life' Mean in a Morphogenetic Society? The Viewpoint of Relational Sociology. in: Margaret Archer, ed., Morphogenesis and Human Fluorishing. 137-162, Springer International Publishing.

Etzioni, Amitai (1968): Social Analysis and Social Action. American Behavioural Scientist 12 (1): 31-33 https://doi.org/10.1177/000276426801200107.

Global Footprint Network (2019): available at http://data.footprintnetwork.org/\#/countryTre nds?cn $=5001$ \& type $=$ BCpc, EFCpc (20 November 2019)

Golob, Tea (2013): Political rituals and nation building: Exploring the Slovenian statehood day. Raziskave in razprave 6 (1): 42-63.

Golob, Tea - Makarovič, Matej (2017): Self-organisation and Development: A Comparative Approach to Post-communist Transformations from the Perspective of Social Systems Theory, Europe-Asia Studies 69 (10): 1499-1525, DOI: 10.1080/09668136.2017.1399198.

Golob, Tea - Makarovič, Matej (2019): Reflexivity and structural positions: The effects of generation, gender and education. Social sciences 8 (9): 1-23.

Government Communication Office (2019): Slovenia among the most successful countries in achieving sustainable development goals again this year. available at https://www.gov.si/en/ news/2019-07-11-slovenia-among-the-most-successful-countries-in-achieving-sustainable-development-goals-again-this-year/ (10 April 2020).

Guardiancich, Igor (2011): The Uncertain Future of Slovenian Exceptionalism. East European Politics and Societies 20 (10): 380-399.

Eurostat (2019): available at https://ec.europa.eu/eurostat/home? (15 December 2019).

ESS Round 4: European Social Survey Round 4 Data (2008): Data file edition 4.5. NSD - Norwegian Centre for Research Data, Norway - Data Archive and distributor of ESS data for ESS ERIC. doi:10.21338/NSD-ESS4-2008. 
ESS Round 7: European Social Survey Round 7 Data (2014): Data file edition 2.2. NSD - Norwegian Centre for Research Data, Norway - Data Archive and distributor of ESS data for ESS ERIC. doi:10.21338/NSD-ESS7-2014.

ESS Round 9: European Social Survey Round 9 Data (2018). Data file edition 2.0. NSD - Norwegian Centre for Research Data, Norway - Data Archive and distributor of ESS data for ESS ERIC. doi:10.21338/NSD-ESS9-2018.

European Values Study (1992): available at https://europeanvaluesstudy.eu (12 March 2020).

ISO 26000 Social Responsibility: available at https://www.iso.org/iso-26000-social-responsibility. html (12 June 2017).

Knio, Karim (2018): The morphogenetic approach and immanent causality: A spinozian perspective. Journal for the Theory of Social Behaviour 48(4): 398-415.

Law, Vincent (2019): Intergenerational and Sustainable Development. in. Leal Filho W. eds. Encyclopedia of Sustainability in Higher Education, Springer, Cham. DOI: https://doi. org/10.1007/978-3-030-11352-0_89-

Lauristin, Marju Vihalemm, Peeter (2020): The 'Estonian way' of the post-communist transformation through the lens of the morphogenetic model, in Kalmus, Veronika - Lauristin, Marju - Opermann, Signe - Vihalemm, Triin, eds.: Researching Estonian Transformation: Morphogenetic Reflections, University of Tartu Press.

Maccarini, Andrea, M. (2017): The Morphogenic Society as a Source and Challenge for Human Fulfillment. in: Margaret Archer, ed., Morphogenesis and Human Fluorishing, 93-114, Springer International Publishing.

Meszmann, Tibor (2007): "(New) Labor Organizations for New Times? Transformation of Trade Unions in Serbia, Slovenia and Poland in 1988-1992/3", unpublished manuscript, November 2007.

Mrak, Mojmir; Rojec, Matija; Silva-Jáuregui, Carlos (2004): Slovenia: From Yugoslavia to the European Union. Washington, Bank: available at https://openknowledge.worldbank.org/ handle/10986/15032 License: CC BY 3.0 IGO." (3 March 2020).

Plut, Dušan (2010): Trajnostni razvoj med mavrico teorij in skromno prakso: available at http:// www.planbzaslovenijo.si/upload/trajnostni-razvoj/plut-besedilo.pdf (12 March 2016).

Pravdić, Velimir (1997): An analysis of sustainable development and environmental protection in postcommunist countries: the case of croatia-a view point, International Journal of Environmental Studies, 53 (3): 195-214, DOI: 10.1080/00207239708711125.

Pretorius, Deon (2020): A Morphogenetic Approach to Social Development. Mistra Urban Futures Report.

Report of the World Commission on Environment and Development: Our Common Future. Brundtland Report 1987: available at https://sustainabledevelopment.un.org/content/ documents/5987our-common-future.pdf (10 February 2020).

Republics of Slovenia, Ministry of Economy (2013): Strategija razvoja Slovenije 2014-2020, Draft. available at http://www.eu-skladi.si/kohezija-do-2013/ostalo/operativni-programi/strategija-razvoja-slovenije (2 February 2020). 
Reuters (2020): Slovenia latest nation to seek carbon neutrality by 2050. available at https:// www.reuters.com/article/us-climate-change-slovenia/slovenia-latest-nation-to-seek-carbon-neutrality-by-2050-idUSKBN1ZD1X8 (20 March 2020).

Robertson, Roland (2014): European Globalization in Global Context, Palgrave Macmillan, Hampshire. SOGESID (2014): The evolution of the "sustainable development" concept. available at http:// www.sogesid.it/english_site/Sustainable_Development.html (10 March 2015).

Special Eurobarometer (2008): Attitudes of European citizens towards the environment: Report. European Commission.

Special Eurobarometer (2014): Attitudes of European Citizens Towards the Environment: Report. European Commission.

Special Eurobarometer (2019): Attitudes of European Citizens Towards the Environment: Report. European Commission.

Spijkers, Otto (2018): Intergenerational Equity and the Sustainable Development Goals. Sustainability 10(11): 3836 https://doi.org/10.3390/su10113836.

Spruk, Rok (2012) After 20 Years of Status Quo: The Failure of Gradualism in Slovenia's Post-Socialist Transition, MPRA Paper No. 36304, available at: http://mpra.ub.uni-muenchen. de/36304/ (14 February 2015).

Sustainable Development Agenda of the United Nations 2030. available at https://sustainabledevelopment.un.org/post2015/transformingourworld (20 January 2020).

Šooš, Timotej et al. (2017): Strategija razvoja Slovenije 2030, Služba Vlade Republike Slovenije za razvoj in evropsko kohezijsko politiko.

Štulhofer, Aleksdandar - Burić, Ivan (2015): Je li egalitarni sindrom samo teorijska fantazija? Empirijski hommage Josipu Županovu. Politička misao 52 (3): 7-31.

Šušteršič, Janez - Rojec, Matija - Korenika, Klavdija (2005): Strategija razvoja Slovenije, Vlada RS, Urad za Makroekonomske analize in razvoj.

Togo, Muchaiteyi (2009): A systems approach to mainstreaming environment and sustainability in universities: the case of Rhodes university, South Africa. Unpiblished PhD Thesis.

Tomšič, Matevž - Vehovar, Urban (2012): Quality of Governance in "Old" and "New" EU Member States in a Comparative Perspective. Sociológia 44 (3): 367-384.

Tomšič, Matevž - Prijon, Lea (2013): Person-based Politics in Italy and Slovenia: Comparing Cases of Leadership's Individualisation. International Social Science Journal 64: 213-214.

Velikonja, Mitja (1996): Masade duha: Razpotja sodobnih mitologij, Znanstveno in publicistično središče, Ljubljana.

Woodward, Susan L. (1995): Socialist Unemployment: The Political Economy of Yugoslavia, 1945-1990. Princeton, NJ: Princeton University Press.

Tea Golob is an associate professor at School of Advanced Social Studies in Nova Gorica/Slovenia.E-mail: tea.golob@fuds.si

Matej Makarovič is a Jean Monnet Chair and a professor at School of Advanced Social Studies in Nova Gorica/Slovenia.E-mail:matej.makarovic@fuds.si 